\title{
Synthesis of Chained Achromatic Layer Systems Forming Controlled Low Transmittance Bands
}

\author{
Mohamed Medhat, Samy S. Farag \\ Physics Department, Faculty of Science, Ain Shams University, Cairo, Egypt \\ E-mail: mmedhat61@hotmail.com \\ Received June 2, 2011; revised July 4, 2011; accepted July 16, 2011
}

\begin{abstract}
The approach utilized in the design of achromatic periods formed of two layers a high-index and a low-index is developed by combining the first two periods together. These two periods are therefore reduced to three layers a central one, an upper layer and a lower layer. Both the upper and lower layers are matched to the central at two different wavelengths. This forms the so called a combined achromatic period or the basic unit. Multilayers showing low transmittance bands are then synthesized of this basic unit. Parameters used in the synthesis of such multilayers are pointed out and their control role is investigated.
\end{abstract}

Keywords: Thin Films, Design, Light Propagation

\section{Introduction}

Recalling the procedure followed in forming two layer combination [1-3] which are matched according to the relation

$$
\begin{gathered}
h_{H}\left(n_{H} G_{H}\right)=h_{L}\left(n_{L} G_{L}\right) \\
\lambda_{o N} \lambda_{o N}
\end{gathered}
$$

where $n_{H}$ and $n_{L}$ are the refractive indices for the highand low-layers, respectively, and the $h$ are the physical thicknesses. Multilayers systems of $N$ such achromatic periods were formed so that each period matched at specified wavelength $\lambda_{o N}$, where $\mathrm{N}$ stands for period number. The different wavelengths, at which the different periods are formed, are specified according to the quantity $\xi$ defined as

$$
\xi=\frac{\lambda_{o N}\left[h_{H}\left(\mathrm{~d} n_{H} / \mathrm{d} \lambda_{o N}\right)-h_{L}\left(\mathrm{~d} n_{L} / \mathrm{d} \lambda_{o N}\right)\right]}{\left[n_{H} h_{H}-n_{L} h_{L}\right]}
$$

In the present work equation (1) is modified to [4]

$$
\begin{array}{rr}
M h_{H}\left(n_{H} G_{H}\right)= & h_{L}\left(n_{L} G_{L}\right) \\
& \lambda_{o N} \quad \lambda_{o N}
\end{array}
$$

where $M$ and $n$ are real numbers [5].

Another modification is introduced here in the multilayer synthesis process. In a previous work $[2,3]$ multilayers of achromatic periods (Equation (1)) were built up by calculating the first achromatic period then subse- quent periods were automatically built up by the way of (1) and (2). In the present work the first achromatic period is calculated by choosing an initial central layer then an upper layer is calculated by matching to this central at the design starting wavelength, by way of (3), then a lower layer is matched to the central at another wavelength. The convention of lower and upper is considered according to positions of substrate and surrounding medium with respect to the first central. Once the above three layers are calculated they are considered as the basic unit. The process of building this basic unit is the same as combining the two middle layers in the first two achromatic periods. Subsequent layers are calculated by considering the lower layer in the basic unit a central for the following layer, in a chained manner, and so on. By this means each layer, except the first and the last layers in whole system, serves as a central layer.

\section{Design}

Six quantities are first specified, namely the film materials, starting wavelength, number of layers, design number $\xi, M$ and $n$. Table 1 shows design details for a multilayer formed of Zinc Sulphide and Cryolite. These materials are chosen here only for illustration without having any particular significance in the theory i.e. any two materials (high and low) will work. The first central layer is chosen as a high index layer which is calculated as a quarter of the starting wavelength $1060 \mathrm{~nm}$. $M$ is 
chosen as $0.77, n$ as 1.3 and $\xi$ as 1.01 . The upper layer, to the air side, is then calculated by way of (3). By way of (2) the second reference Wavelength, after the starting wavelength, is then calculated and then the lower layer by way of (3) is calculated but at the second reference. It is worth mentioning here that the first central layer may be chosen as a low index as well. This will not affect our design approach. This last calculated layer is then considered the central for the subsequent layer, a new reference wavelength, by way of (2), and so on.

Design details are listed in Table $\mathbf{1}$ and the resulting transmittance spectrum in Figure 1 shows high-transmittance bands alternating with low transmittance bands [6]. The transmittance simulations are performed by means of a program based on an algorithm presented by Liddell [7]. Throughout this paper only the region of spectrum including the central second order low transmittance band approx. $400 \mathrm{~nm}$ - $900 \mathrm{~nm}$ will be considered.

\section{Illustrations}

If in the above design all calculations are done by way of (1) instead of (3) ( $M=1, n=1)$ and $\xi$ also taken as unity the resulting design is listed in Table 2. Setting all parameters to unity results in the suppression of the central minimum and all even orders (Figure 2). Comparing with thicknesses in Table $\mathbf{1}$ it can be seen that increasing the ratio $h_{L} / h_{H}$ is one way for keeping transmittance minima in place. Another way is assigning $\xi$ values bigger than unity. This is shown in the design listed in Table 3 and the resulting transmittance curve in Figure 3. Notice the appearance of central minimum but in a de-

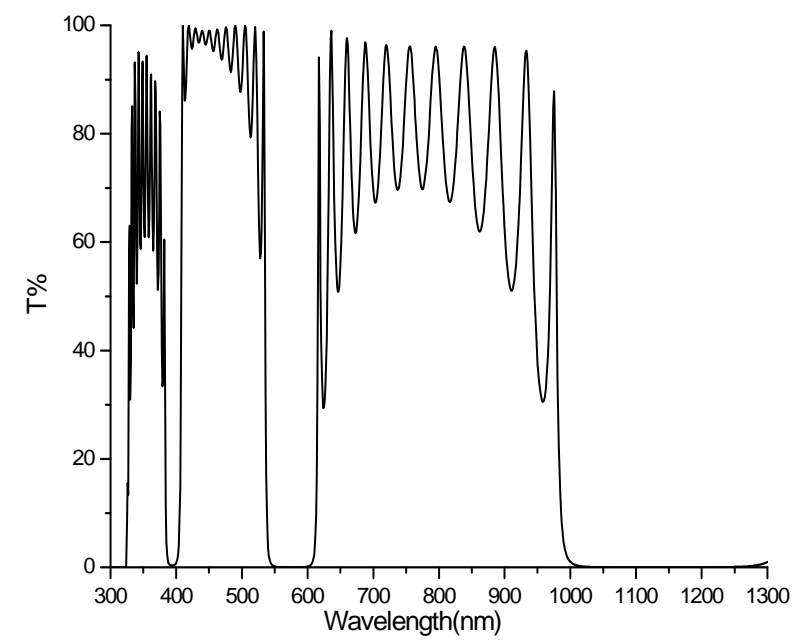

Figure 1. Transmittance spectrum for design listed in Table 1. Increasing the ratio $h_{L} / h_{H}$ is one way for manifesting the second order central minimum in addition to enhancing $\mathrm{T} \%$ on the short wave side of this central minimum.
Table 1. Design details for initial parameters: Start wave: 1060, $\xi: 1.01, M: 0.77, n: 1.3$ no of layers: 25 . Every reference wave for every layer is the wavelength matching this layer to the next layer in the table.

\begin{tabular}{|c|c|c|c|}
\hline $\begin{array}{c}\text { Layer } \\
\text { no. }\end{array}$ & $\begin{array}{l}\text { Physical Thickness } \\
\text { (after multiplication by } \\
M \text { or } M \text { in nm) }\end{array}$ & Material & $\begin{array}{l}\text { Reference } \\
\text { waves } \lambda_{0} \\
(\mathrm{~nm})\end{array}$ \\
\hline 0 & & Air & \\
\hline 1 & 264 & Cryolite & 1060 \\
\hline 2 & 91 & $\mathrm{ZnS}$ & 373 \\
\hline 3 & 265 & - & 372 \\
\hline 4 & 90.7 & - & 371 \\
\hline 5 & 266 & - & 370 \\
\hline 6 & 90.4 & - & 369 \\
\hline 7 & 267 & - & 368 \\
\hline 8 & 90.1 & - & 367 \\
\hline 9 & 268 & - & 366 \\
\hline 10 & 89.8 & - & 365 \\
\hline 11 & 269 & - & 364.9 \\
\hline 12 & 89.5 & - & 364 \\
\hline 13 & 270 & - & 363 \\
\hline 14 & 89.1 & - & 362 \\
\hline 15 & 271 & - & 361 \\
\hline 16 & 88.8 & - & 360 \\
\hline 17 & 272 & - & 359 \\
\hline 18 & 88.4 & - & 358 \\
\hline 19 & 273 & - & 357 \\
\hline 20 & 88.1 & - & 356 \\
\hline 21 & 274 & - & 355 \\
\hline 22 & 87.8 & & 354 \\
\hline 23 & 275 & & 353 \\
\hline 24 & 87.4 & & 352 \\
\hline \multirow[t]{2}{*}{25} & 276 & & \\
\hline & Substrate & Glass & \\
\hline
\end{tabular}

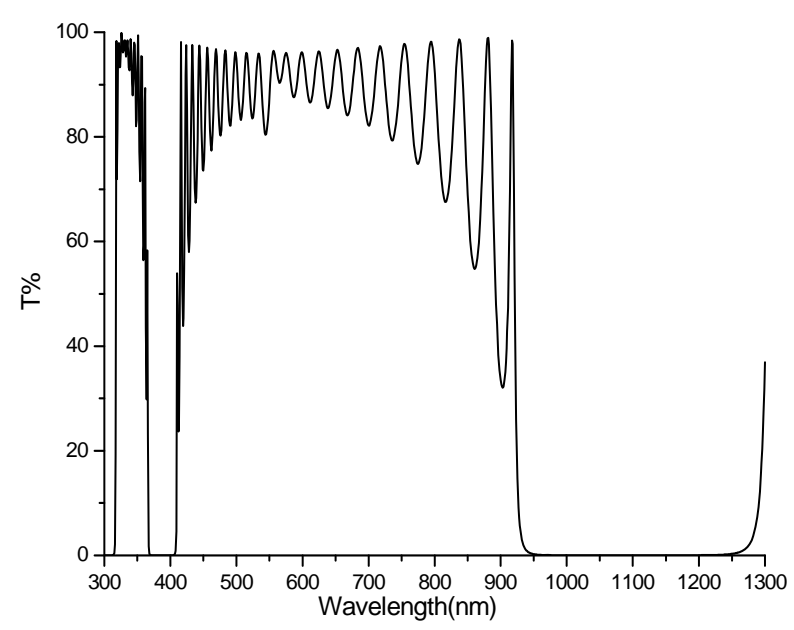

Figure 2. Transmittance spectrum for design listed in Table 2. When $\xi, M$ and $M$ are taken as unity the second order central minimum is suppressed. 


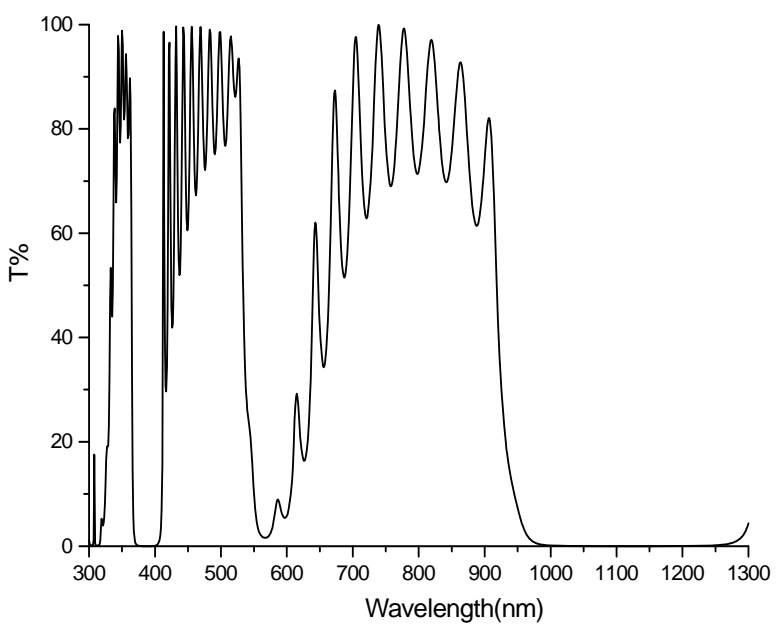

Figure 3. Transmittance spectrum for design listed in Table 3. Increasing $\xi$ is another way for exhibiting the second order central minimum.

Table 2. Design details for initial parameters: Start wave: 1060, $\xi: 1, m: 1$, $n: 1$ no of layers: 25 . Reference wavelength the same for all layers.

\begin{tabular}{|c|c|c|c|}
\hline $\begin{array}{c}\text { Layer } \\
\text { no. }\end{array}$ & $\begin{array}{l}\text { Physical Thickness } \\
\text { (after multiplication by } \\
M \text { or } M \text { in nm) }\end{array}$ & Material & $\begin{array}{c}\text { Reference } \\
\text { waves } \\
\lambda_{0}(\mathrm{~nm}) \\
\end{array}$ \\
\hline 0 & & Air & \\
\hline 1 & 203 & Cryolite & 1060 \\
\hline 2 & 118 & $\mathrm{ZnS}$ & - \\
\hline 3 & 203 & - & - \\
\hline 4 & 118 & - & - \\
\hline 5 & 203 & - & - \\
\hline 6 & 118 & - & - \\
\hline 7 & 203 & - & - \\
\hline 8 & 118 & - & - \\
\hline 9 & 203 & - & - \\
\hline 10 & 118 & - & - \\
\hline 11 & 203 & - & - \\
\hline 12 & 118 & - & - \\
\hline 13 & 203 & - & - \\
\hline 14 & 118 & - & - \\
\hline 15 & 203 & - & - \\
\hline 16 & 118 & - & - \\
\hline 17 & 203 & - & - \\
\hline 18 & 118 & - & - \\
\hline 19 & 203 & - & - \\
\hline 20 & 118 & - & - \\
\hline 21 & 203 & - & - \\
\hline 22 & 118 & & - \\
\hline 23 & 203 & & - \\
\hline 24 & 118 & & - \\
\hline \multirow[t]{2}{*}{25} & 203 & & \\
\hline & Substrate & Glass & \\
\hline
\end{tabular}

Table 3. Design details for initial parameters: Start wave: 1060, $\xi: 1.25$, $m: 1, n: 1$ no of layers: 25. Every reference wave for every layer is the wavelength matching this layer to the next layer in the table.

\begin{tabular}{|c|c|c|c|}
\hline $\begin{array}{c}\text { Layer } \\
\text { no. }\end{array}$ & $\begin{array}{l}\text { Physical Thickness } \\
\text { (after multiplication by } \\
m \text { or } M \text { in } \mathrm{nm} \text { ) }\end{array}$ & Material & $\begin{array}{c}\text { Reference } \\
\text { waves } \\
\lambda_{0}(\mathrm{~nm})\end{array}$ \\
\hline 0 & & Air & \\
\hline 1 & 203 & Cryolite & 1060 \\
\hline 2 & 118 & $\mathrm{ZnS}$ & 983 \\
\hline 3 & 205 & - & 913 \\
\hline 4 & 117 & - & 848 \\
\hline 5 & 207 & - & 789 \\
\hline 6 & 115 & - & 735 \\
\hline 7 & 210 & - & 686 \\
\hline 8 & 113 & - & 642 \\
\hline 9 & 214 & - & 603 \\
\hline 10 & 111 & - & 568 \\
\hline 11 & 219 & - & 536 \\
\hline 12 & 108 & - & 508 \\
\hline 13 & 227 & - & 482 \\
\hline 14 & 104 & - & 459 \\
\hline 15 & 236 & - & 437 \\
\hline 16 & 99 & - & 417 \\
\hline 17 & 249 & - & 397 \\
\hline 18 & 93 & - & 378 \\
\hline 19 & 267 & - & 359 \\
\hline 20 & 87 & - & 335 \\
\hline 21 & 289 & - & 277 \\
\hline 22 & 79 & & 275 \\
\hline 23 & 320 & & 272 \\
\hline 24 & 71 & & 269 \\
\hline \multirow[t]{2}{*}{25} & 364 & & \\
\hline & Substrate & Glass & \\
\hline
\end{tabular}

formed state. Here appears the refining effect of $m$ and $n$.

Increasing the ratio $h_{L} / h_{H}$ further by way of $M$ and $n$ results in broadening the central minimum with respect to the spectrum. This is shown in Figure 4.

Concerning the transmittance fluctuations on either side [8-11] of the central minimum it is seen from Figures $\mathbf{1}$ and $\mathbf{3}$ that ripple on the short wavelength side is less obvious than that on the long wavelength side. This is another effect of increasing the ratio $h_{L} / h_{H}$.

If the opposite is done by increasing the ratio $h_{H} / h_{L}$, ripple on the long wavelength side is greatly improved as shown in Figure 5. Figure 6 is a further illustration for this last design which is extended to 35 layers as an in- 


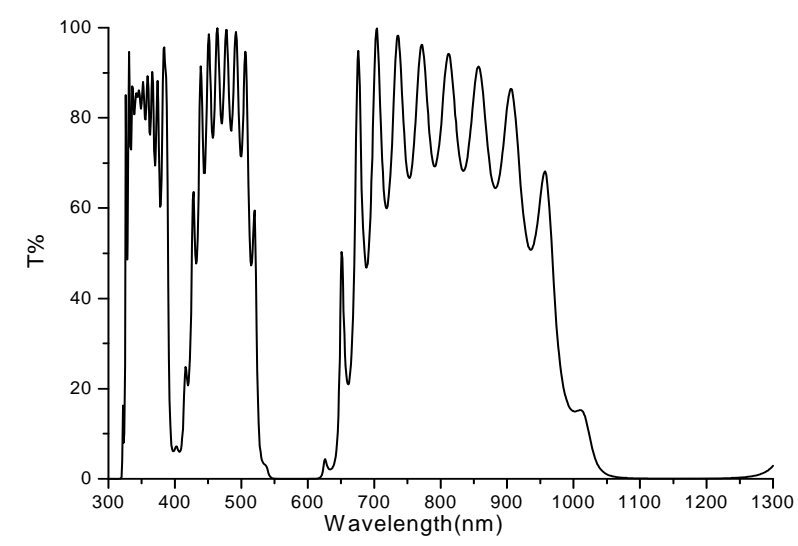

Figure 4. Transmittance spectrum for design listed in Table 4. Increasing the ratio $h_{L} / h_{H}$ further results in broadening the central minimum with respect to the spectrum.

Table 4. Design details for initial parameters: Start wave: 1060, $\xi: 1.04, M: 0.75, n: 1.5$ no of layers: 25 . Every reference wave for every layer is the wavelength matching this layer to the next layer in the table.

\begin{tabular}{|c|c|c|c|}
\hline $\begin{array}{c}\text { Layer } \\
\text { no. }\end{array}$ & $\begin{array}{l}\text { Physical Thickness } \\
\text { (after multiplication by } \\
M \text { or } M \text { in nm) }\end{array}$ & Material & $\begin{array}{c}\text { Reference } \\
\text { waves } \\
\lambda_{0}(\mathrm{~nm}) \\
\end{array}$ \\
\hline 0 & & Air & \\
\hline 1 & 271 & Cryolite & 1060 \\
\hline 2 & 78 & $\mathrm{ZnS}$ & 278 \\
\hline 3 & 276 & - & 277.3 \\
\hline 4 & 77 & - & 277.9 \\
\hline 5 & 281 & - & 277.5 \\
\hline 6 & 76 & - & 277.1 \\
\hline 7 & 286 & - & 276.7 \\
\hline 8 & 74 & - & 276.3 \\
\hline 9 & 291 & - & 275 \\
\hline 10 & 73 & - & 274.9 \\
\hline 11 & 298 & - & 274.4 \\
\hline 12 & 71 & - & 273.9 \\
\hline 13 & 304 & - & 273.4 \\
\hline 14 & 70 & - & 272.9 \\
\hline 15 & 311 & - & 272.4 \\
\hline 16 & 68 & - & 271.8 \\
\hline 17 & 319 & - & 271.2 \\
\hline 18 & 66 & - & 270.6 \\
\hline 19 & 327 & - & 270 \\
\hline 20 & 65 & - & 269 \\
\hline 21 & 335 & - & 268.8 \\
\hline 22 & 63 & & 268.2 \\
\hline 23 & 343 & & 267 \\
\hline 24 & 62 & & 266 \\
\hline \multirow[t]{2}{*}{25} & 353 & & \\
\hline & Substrate & Glass & \\
\hline
\end{tabular}

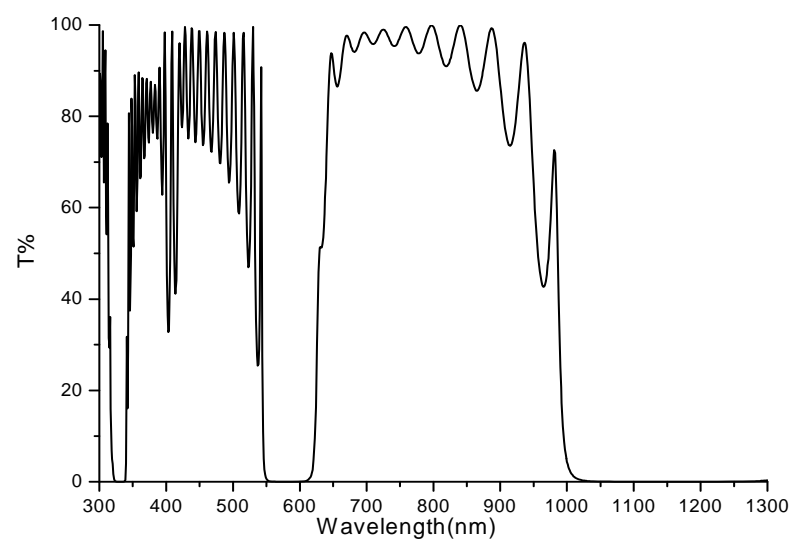

Figure 5. Transmittance spectrum for design listed in Table 5 . Increasing the ratio $h_{H} / h_{L}$ instead of $h_{L} / h_{H}$ improves ripple on the long wavelength side of the central minimum.

Table 5. Design details for initial parameters: Start wave: $1060, \xi: 1.12, m: 1.4, n: 0.7$ no of layers: 25 . Every reference wave for every layer is the wavelength matching this layer to the next layer in the table.

\begin{tabular}{|c|c|c|c|}
\hline $\begin{array}{c}\text { Layer } \\
\text { no. }\end{array}$ & $\begin{array}{l}\text { Physical Thickness } \\
\text { (after multiplication by } \\
M \text { or } M \text { in nm) }\end{array}$ & Material & $\begin{array}{c}\text { Reference } \\
\text { waves } \\
\lambda_{0}(\mathrm{~nm})\end{array}$ \\
\hline 0 & & Air & \\
\hline 1 & 145 & Cryolite & 1060 \\
\hline 2 & 169 & $\mathrm{ZnS}$ & 1019 \\
\hline 3 & 146 & - & 980 \\
\hline 4 & 168 & - & 943 \\
\hline 5 & 146 & - & 908 \\
\hline 6 & 167 & - & 874 \\
\hline 7 & 147 & - & 841 \\
\hline 8 & 166 & - & 810 \\
\hline 9 & 148 & - & 780 \\
\hline 10 & 165 & - & 752 \\
\hline 11 & 149 & - & 725 \\
\hline 12 & 164 & - & 700 \\
\hline 13 & 150 & - & 676 \\
\hline 14 & 162 & - & 653 \\
\hline 15 & 152 & - & 632 \\
\hline 16 & 161 & - & 611 \\
\hline 17 & 154 & - & 592 \\
\hline 18 & 159 & - & 574 \\
\hline 19 & 156 & - & 557 \\
\hline 20 & 156 & - & 541 \\
\hline 21 & 158 & - & 526 \\
\hline 22 & 154 & & 512 \\
\hline 23 & 161 & & 498 \\
\hline 24 & 151 & & 485 \\
\hline \multirow[t]{2}{*}{25} & 164 & & \\
\hline & Substrate & Glass & \\
\hline
\end{tabular}


Table 6. Design details for initial parameters: Start wave: $1060, \xi: 1.12, m: 1.4, n: 0.7$ no of layers: 35 . Every reference wave for every layer is the wavelength matching this layer to the next layer in the table.

\begin{tabular}{|c|c|c|c|}
\hline $\begin{array}{c}\text { Layer } \\
\text { no. }\end{array}$ & $\begin{array}{l}\text { Physical Thickness } \\
\text { (after multiplication by } \\
M \text { or } M \text { in nm) }\end{array}$ & Material & $\begin{array}{c}\text { Reference } \\
\text { waves } \\
\lambda_{0}(\mathrm{~nm}) \\
\end{array}$ \\
\hline 0 & & Air & \\
\hline 1 & 145 & Cryolite & 1060 \\
\hline 2 & 169 & ZnS & 1019 \\
\hline 3 & 146 & - & 980 \\
\hline 4 & 168 & - & 943 \\
\hline 5 & 146 & - & 908 \\
\hline 6 & 167 & - & 874 \\
\hline 7 & 147 & - & 841 \\
\hline 8 & 166 & - & 810 \\
\hline 9 & 148 & - & 780 \\
\hline 10 & 165 & - & 752 \\
\hline 11 & 149 & - & 725 \\
\hline 12 & 164 & - & 700 \\
\hline 13 & 150 & - & 676 \\
\hline 14 & 162 & - & 653 \\
\hline 15 & 152 & - & 632 \\
\hline 16 & 161 & - & 611 \\
\hline 17 & 154 & - & 592 \\
\hline 18 & 159 & - & 574 \\
\hline 19 & 156 & - & 557 \\
\hline 20 & 156 & - & 541 \\
\hline 21 & 158 & - & 526 \\
\hline 22 & 154 & & 512 \\
\hline 23 & 161 & & 498 \\
\hline 24 & 151 & & 485 \\
\hline 25 & 164 & & 472 \\
\hline 26 & 148 & & 460 \\
\hline 27 & 167 & & 449 \\
\hline 28 & 145 & & 438 \\
\hline 29 & 172 & & 427 \\
\hline 30 & 141 & & 417 \\
\hline 31 & 177 & & 407 \\
\hline 32 & 137 & & 397 \\
\hline 33 & 182 & & 387 \\
\hline 34 & 132 & & 378 \\
\hline \multirow[t]{2}{*}{35} & 189 & & \\
\hline & Substrate & Glass & \\
\hline
\end{tabular}

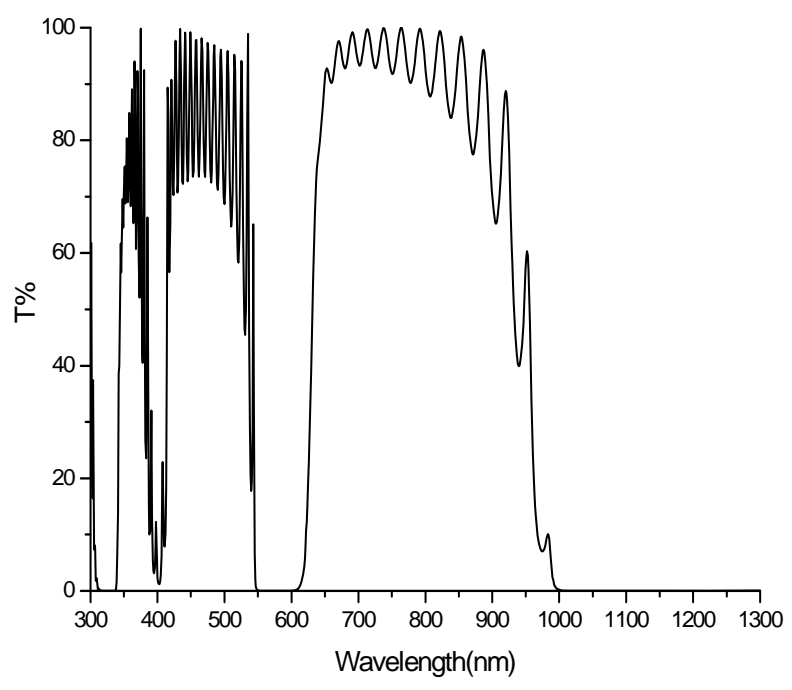

Figure 6. Transmittance spectrum for design listed in Table 6. Increasing no. of layers in the previous design affects the low transmittance bands rather than the high ones.

vestigation for the effect of increasing no. of layers. Although the reflection bands are got more defined the transmittance ones are seriously affected.

\section{Conclusions}

A new approach for synthesizing optical multilayer structures is presented. The resulting transmittance spectrum is also studied. The essential modifications to the basic theory introduced effective elements which revealed valuable control on the transmittance spectral characteristics of the variety of systems under study. Those control actions also unveiled useful applications for the systems presented.

\section{References}

[1] M. Medhat and S. S. Farag, "The Effect of the Group Propagation of Waves on the Spectral Behavior of a Multilayer Ar Coating,” Optics \& Laser Technology, Vol. 30, No. 1, 1998, pp. 57-61.

[2] M. Medhat and S. S. Farag, “Achromatic Layers Applied to Dielectric Filters," Journal of Optics A: Pure and Applied Optics, Vol. 2, No. 6, 2000, pp. 529-533. doi:10.1088/1464-4258/2/6/305

[3] M. Medhat and S. S. Farag, "Broad-Band Dielectric Multilayer Mirrors by Period Staggering,” Journal of Optics A: Pure and Applied Optics, Vol. 3, No. 3, 2001, pp. 178-182. doi:10.1088/1464-4258/3/3/304

[4] M. Medhat, "Interferometric Comparison of Optical Pathlengths: Rings of Equal Chromatic Order," Optik, Vol. 84, No. 3, 1990, pp. 77-82

[5] R. W. Ditchburn, “Light,” Academic Press Inc., London, 1976, p. 65. 
[6] A. Thelen, "Multilayer Filters with Wide Transmittance Bands," Journal of the Optical Society of America, Vol. 53, No. 11, 1963, pp. 1266-1270. doi:10.1364/JOSA.53.001266

[7] H. M. Liddell, "Computer-Aided Techniques for the Design of Multilayer Filters,” Adam Hilger, Bristol, 1981.

[8] W. T. Welford, "Computations in Thin Film Optics," Vacuum, Vol. 4, No. 1, 1954, pp. 3-19.

[9] P. W. Baumeister, "Design of Multilayer Filters by Successive Approximations,” Journal of the Optical Society of America, Vol. 48, No. 12, 1958, pp. 955-958. doi:10.1364/JOSA.48.000955

[10] R. Jacobsson, "Matching a Multilayer Stack to a High-Refractive-Index Substrate by Means of an Inhomogeneous Layer," Journal of the Optical Society of America, Vol. 54, No. 3, 1964, pp. 422-423. doi:10.1364/JOSA.54.0422_1

[11] L. Young and E. G. Cristal, "On a Dielectric Fiber by Baumeister,” Applied Optics, Vol. 5, 1966, pp. 77-80. doi:10.1364/AO.5.000077 